\title{
Implicações da Gestalt-terapia Frente às Relações de Hiperconsumo
}

\author{
Gestalt Therapy Implications for Hyperconsuption Relations
}

\section{Implicaciones de la Terapia Gestalt para las Relaciones de Hiperconsumo}

\author{
Carla Machado Alegria* \\ Universidade Veiga de Almeida - UVA, Cabo Frio, Rio de Janeiro, Brasil
}

\begin{abstract}
RESUMO
A hipermodernidade, com suas bases culturais fundamentadas no individualismo e nas relações de consumo, levou o homem a um completo esgotamento frente às expectativas de felicidade a ser obtida por meio da conquista de melhores desempenhos em vários aspectos da existência e em aquisições materiais. Uma vez que o indivíduo está constantemente exposto às consequências do modus vivendi do hiperconsumo, qual seja, o caráter transitório do sucesso que provoca o sentimento de fracasso, são observadas sequelas emocionais que podem se desdobrar em fenômenos psicopatológicos contemporâneos, sendo alguns destes destacados no artigo. O objetivo deste trabalho é apontar como a força do imperativo do sucesso pode intensificar sentimentos como humilhação, vergonha e inveja, assim como sugerir a Gestalt-terapia como oportunidade de libertação da opressora ideologia da superação de si, por ser, pelo encontro dialógico, um instrumento na sustentação da dignidade do sujeito diante das desconfirmações a que é constantemente submetido.

Palavras-chave: felicidade, vergonha, inveja, gestalt-terapia.
\end{abstract}

\begin{abstract}
Hypermodernity, with its cultural foundations based on individualism and consumer relations, led human beings to a complete exhaustion in face of the expectations of happiness to be obtained through the achievement of better performances in various aspects of existence and in material acquisitions. Since the individual is constantly exposed to the consequences of the hyperconsumption modus vivendi, that is, the transitory character of success that causes the feeling of failure, emotional sequelae can be observed that may unfold into contemporary psychopathological phenomena, some of which are highlighted in the article. The aim of this paper is to point out how the strength of the success imperative can intensify feelings such as humiliation, shame, and envy, as well as suggest Gestalt-therapy as an opportunity for liberation from the oppressive ideology of self-overcoming, because, through the dialogical encounter, it is an instrument for sustaining the dignity of the subject in the face of the disconfirmations to which he/she is constantly exposed.
\end{abstract}

Keywords: happiness, shame, envy, gestalt-therapy. 


\begin{abstract}
RESUMEN
La hipomordenidad, con su bases culturales fundamentadas en el individualismo y en las relaciones de consumo, ha llevado al hombre a un agotamiento completo ante las expectativas de felicidad a ser obtenida por medio de la conquista de mejores desempeños en diversos aspectos de la existencia y en las adquisiciones materiales. Una vez que el indivíduo está constantemente expuesto a las consecuencias del modus vivendi del hiperconsumo, culquiera que sea, el carácter transitorio del suceso que provoca el sentimiento de fracaso, son observadas secuelas emocionales que pueden desplegarse en los fenómenos psicopatológicos contemporáneos, algunos de los cuales se destacan en el artículo. El objetivo de este trabajo es señalar cómo la fuerza del imperativo del suceso puede intensificar sentimientos como humillación, vergüenza y envidia, así como sugerir que la terapia Gestalt como una oportunidad de liberación de la ideologia opresiva de superación personal, por ser, a través del encuentro dialógico, un instrumento para sostener la dignidad del sujeto frente a las desconfirmaciones a las que está constantemente sometido.
\end{abstract}

Palabras clave: felicidad, vergüenza, envidia, terapia gestalt.

A nossa sociedade do hiperconsumo, que estimula a satisfação de desejos imediatos, tornou o sujeito cada vez mais voltado para princípios particulares. As demandas de consumo, ao mesmo tempo em que estão voltadas para aquisição, em altas velocidades, de novas tecnologias que ampliam as experiências humanas para um universo digitalizado em detrimento das experiências sensíveis e corporificadas, estão também orientadas por referenciais narcísicos. Nós estamos mais voltados para a promoção de melhores condições de vida e conforto; buscamos uma vida mais saudável e espiritualizada, assim como melhora obsessiva da aparência física e bem-estar interior. Precisamos estar no topo de nosso potencial na preservação de nossa saúde física e emocional. A Organização Mundial da Saúde parece ter incorporado bem esse apelo consumista quando ainda sustenta a definição de saúde como um estado completo de bem-estar, incluindo os aspectos físico, mental e social (WHO - World Health Organization, 1946).

Estamos mergulhados numa ideologia de superação de si que nos impulsiona a explorar ao máximo nosso potencial, perseguindo sempre nosso melhor desempenho numa demonstração de poder. Ao contrário do que possa parecer, o culto aos cuidados corporais e à saúde mental nos faz perseguir um estado de estar sempre, simplesmente, muito bem. A busca da felicidade interior se impõe como um ideal supremo e torna-se um segmento de mercado: algo que todos, pelo esforço pessoal, podem conquistar.

Desse modo, quando a felicidade é prometida a todos, e o sentido de obtê-la está relacionado, de modo amplo, às exigências de ser e de viver melhor, às conquistas sem limite de bens materiais, de lazer e satisfação completa em bem-estar, proporcionalmente as 
possibilidades de decepção e desapontamento se alargam. O nosso valor passou a ser baseado no sucesso-fracasso de obter essas conquistas. Nesse sentido, estamos diante de uma felicidade paradoxal. "As solicitações hedonísticas são onipresentes: as inquietações, as decepções, as inseguranças sociais e pessoais aumentam." (Lipovetsky, 2007, p. 17).

Embora o enaltecimento da autonomização do indivíduo, sustentada sob a ideologia da superação de si e mantida sob as garras do ideário liberal e neoliberal, tenha perpetuado a crença da igualdade inata de todos os seres humanos para realizarem o que quiserem, os nossos desapontamentos e decepções são experiências que desconfirmam essa tese. Se, antes, as situações de fracasso eram vistas como um destino de classe, hoje, como aponta Lipovetsky (2015), o êxito e o fracasso são atribuídos à nossa exclusiva responsabilidade, e amargamos o sofrimento moral de não estarmos à altura de construirmos a nós mesmos. Com isso, torna-se impossível, para nós, mantermos a nossa autoconfiança quando imaginamos ou sentimos que os outros deixaram de nos ver com respeito.

\section{O estigma e suas consequências emocionais}

A experiência do estigma se estrutura em quem fica à margem dos ideais da cultura do consumo. Segundo Bauman, em suas obras "Vida para consumo" (2008) e "Estranhos à nossa porta" (2017), ecoando Erving Goffman (1963) em seu livro "Estigma: Notas sobre a Manipulação da Identidade Deteriorada", os estigmatizados são considerados como possuidores de uma anomalia, visto que possuem uma característica considerada uma anormalidade. Afinal, os normais são considerados aqueles que correspondem às expectativas da sociedade. As pessoas estigmatizadas são repelidas e sofrem os tormentos da humilhação e da vergonha, experiências emocionais que resultam em autodepreciação e autodesprezo. Em outro momento, o autor menciona que essas pessoas são consideradas os danos colaterais dessa sociedade. Sentem-se os verdadeiros refugos humanos, pois fazem parte de uma "subclasse", composta pelos incapacitados; pessoas que encarnam a própria imagem da falência. Não conseguem atender ao imperativo da performance e são inábeis para adentrar à sociedade de consumidores por não conseguirem alcançar os esperados padrões de desempenho. Assim, a responsabilidade da sua incompetência é depositada sobre si mesmas. $\mathrm{E}$, como cada indivíduo sente que está bem distante do que poderia ser ou gostaria de ser, o sentimento de uma vergonhosa inadequação instaura, naquele que está fora do padrão, uma angústia perene. 
Essa lógica perversa do liberalismo cumpriu bem a função de sustentar e ampliar aquele sentimento com o qual secretamente convivemos desde criança: não somos suficientemente bons, por isso não merecermos amor, admiração e respeito. Por vermos, na reprodução do espelho, a única imagem refletida do olhar de nossos pais sobre nós, é nela que acreditamos, e também, por muito tempo, será a única maneira que nós nos veremos. Ainda quando adultos, a concepção que temos de nós continua dependendo muito do que os outros pensam a nosso respeito. Se não nos adequamos aos ideais de sucesso, podemos perder o respeito. Portanto, como conclui De Botton (2014), o que move nosso desejo de status talvez não seja os bens ou o sucesso que podemos adquirir, mas o amor, o respeito e a atenção que recebemos em decorrência do status que alcançamos.

Como para garantirmos nosso lugar ao sol, sentirmos orgulho de nós mesmos, ficarmos felizes e satisfeitos, precisamos conquistar cada vez mais status e ter melhor desempenho em vários aspectos da nossa vida, facilmente, então, somos apanhados pela lógica do aperfeiçoamento pelo aperfeiçoamento. No entanto, como os valores associados à felicidade têm existência transitória, podemos fracassar e nunca nos sentirmos amados. Como defesa a esses sentimentos, muitos de nós desenvolvemos uma necessidade urgente de estarmos em um patamar superior ao que estamos, o que nos leva a extrapolar os limites da razão e nos torna aprisionados a esse objetivo como garantia de obtermos o amor. Assim, impelidos por ilimitados desafios de conquistarmos algum sucesso, nos enredamos na compulsão. Em nossos termos, à gestalt que não fecha.

Recebem-se, à procura de terapia, pessoas que estão enredadas na luta para obterem o melhor padrão. Pessoas que já conquistaram algum status, mas, como essa busca não tem fim, aceitaram, interminavelmente, novos desafios, explorando seu potencial a todo custo e chegaram à exaustão: em crise de pânico, com compulsões, episódios de mania e depressão.

Birman (1999), em seu estudo sobre as psicopatologias na pósmodernidade, destaca a necessidade de situarmos a temporalidade histórica para compreendermos o sentido das psicopatologias de determinada época. Baseando-se na sua experiência clínica e no levantamento de outros estudos publicados, afirma que, em função de vivermos numa sociedade exibicionista na qual tem valor quem sabe e está à altura de se exibir com brilho como produto a ser exposto como mercadoria, as pessoas que têm um estilo mais sofredor, uma interiorização excessiva, estão deprimidas ou com síndrome do pânico, representam a impossibilidade de fazerem parte da sociedade do espetáculo. São execradas.

Assim, as toxicomanias situam-se junto às depressões e à síndrome do pânico como as psicopatologias atuais. Como descreve, de forma sensível, Birman (1999): 
. . . para os ferrados, que não conseguem dizer 'cheguei', de peito inflado, a fórmula mágica é a alquimia, para mudar a circulação dos humores. É preciso dar uma pancada química na bílis negra, nos dizem os novos especialistas da alma sofrentes. Por este meio seria possível, acreditam aqueles, retirar as individualidades do cenário dark e inseri-las na cena colorida da representação e do espetáculo. (Birman, 1999, p. 47).

Desse modo, a função dos psicofármacos é recuperar a potência daqueles que estão à margem para chegarem ao nível de "bons" cidadãos.

Moore (1993), traçando reflexões sobre o papel da depressão na sociedade contemporânea, nos traz uma compreensão que merece destaque. Para o autor, a depressão pode ser reflexo de um alívio de não ser preciso permanecer no esgotamento de carregar a armadura da felicidade em incansáveis novas performances.

Referindo-se à tendência da nossa sociedade de ser dedicada à luz e à felicidade, sugere que existe uma rejeição generalizada a tudo que é sombrio e cinzento. Estamos sempre nos defendendo do lado trágico da vida, logo a depressão é vista como o grande inimigo a ser vencido. Desse modo, ela acaba surgindo com força tamanha, como uma compensação, reivindicando seu lugar na experiência da pessoa. Ressalta ainda que precisamos acolher a depressão como mais um estado da existência, como um ritmo próprio da vida, sem colocarmos juízo de valor em sua chegada. Não vê-la nem como má, nem como boa, mas como mais um aspecto da existência que tem qualidades sombrias e que pode nos ensinar algo. Talvez, nos momentos em que ela, como outra emoção na vida, se apresente de forma completamente debilitante, seja muito difícil para nós aceitá-la. Mesmo assim, se não quisermos extirpá-la, ela terá algo a nos ensinar.

De outro modo, para terapia, recebem-se pessoas humilhadas e esmagadas pela vergonha. Embora desejo e decepção sejam parte da condição humana, na nossa sociedade individualista a decepção incorporou um peso a mais, visto que passou a ser vivenciada de forma associada à humilhação e à vergonha de si mesmo.

Como ressalta De Botton (2014), a humilhação é a constatação dolorosa de que não conseguimos que o mundo reconheça nosso valor. Podemos inferir que a humilhação a que somos lançados desenvolve em nós a inveja pelos bem-sucedidos e passamos a sentir vergonha de nós mesmos.

Segundo Guiddens (2002), na modernidade tardia, as metas intermináveis a serem alcançadas geram decepções quando os objetivos não são atingidos, e essa vivência é sentida como uma limitação da pessoa, o que provoca sentimentos de inadequação e 
humilhação. "A vergonha é provocada por sentimentos de insuficiência pessoal que podem incluir um elemento da constituição psicológica do indivíduo desde muito cedo na vida." (Guiddens, 2002, p. 66).

Para o autor, nos tempos da modernidade é a vergonha, e não a culpa, o sentimento mais predominante na experiência pessoal. Ela está ligada a um sentimento de insegurança, uma vez que esse sentimento pode ameaçar ou corroer a confiança básica. Sustentando essa concepção, conclui: "A vergonha ataca as raízes da confiança mais que a culpa, porque a vergonha está envolvida de maneira fundamental com o temor do abandono na infância." (Guiddens, 2002, p. 66).

Como o que introjetamos quando criança é a afirmação de que não somos suficientemente bons, somos vítimas de nossos próprios julgamentos negativos, os quais nos devolvem uma imagem depreciada de nós próprios. Então, projetamos essa visão no olhar do outro, que acreditamos, sem escapatória, irá nos rejeitar. De acordo com Robine (2006, p. 165) ". . . vergonha e rejeição se encontram associadas, e podemos dizer que a minha vergonha está ligada a uma projeção da rejeição do outro".

Ela emerge, portanto, quando a nossa insuficiência baseada na comparação fica exposta. "A vergonha é a consequência direta do conhecimento - da awareness, diríamos nós, da consciência de si - e é imediatamente associada à exposição de si mesmo, à nudez ao olhar do outro." (Robine, 2006, p. 155). O aumento do nível do desejo nos faz sentir que o que somos não é suficiente, e a noção do que é suficiente para sustentar a nossa autoestima provém da comparação.

Nesse aspecto, reside o problema. A comparação é um solo fértil para o desenvolvimento de uma autodepreciação. Nós e a nossa própria história não somos a base da nossa própria comparação. Além do mais, se a vergonha tem a ver com estar exposto ao olhar do outro, numa sociedade exibicionista como a nossa, estamos sempre nos deparando com nossa insuficiência, o que leva a uma reação em cadeia interminável de vergonha, mais ainda, de vergonha da própria vergonha.

Precisamos, desse modo, renovar nossa atenção em terapia, pois conforme Lewis (1971), a vergonha é a mais frequente emoção nas sessões de psicoterapia. Por ser da sua natureza esconder-se, ela se torna subterrânea e virtualmente invisível. Está, consequentemente, pouco disponível a awareness do cliente e do terapeuta desavisado.

Outrossim, é importante repensarmos a maneira de entender os afetos e os atributos humanos até hoje vistos dentro de uma perspectiva maniqueísta e preconceituosa, divididos em bem e mal, certo e errado, belo e feio. É assim que estigmatizamos a inveja como pecaminosa e destrutiva. 
De acordo com Lipowetsky (2007), a civilização consumista intensifica sentimentos de ciúme, rivalidades e competições. E a inveja é compreendida como um sentimento de desprazer, quando uma pessoa percebe a felicidade e o sucesso de um outro, semelhante a ele, e sente uma alegria sendo despertada em si quando constata a privação das vantagens de que desfruta esse outro.

O mesmo autor, ao se referir ao lugar da inveja nos tempos hipermodernos, nos adverte de que o que inspira a inveja nesse contexto são fatores relacionados a satisfações privadas, intimizadas, como é o caso de conquistar ". . . prestígio, celebridade, talento, vitória, promoção profissional, beleza, sedução, conquista amorosa e felicidade de ser amado . . ." (Lipovetsky, 2007, p. 328).

Precisamos, assim, ficar atentos a esses fatores desencadeadores da inveja nas relações de consumo para que possamos estar abertos a perceber a sua presença em terapia. Em nossa sociedade patriarcal, herdeira das repressões da inquisição, a inveja é enfatizada apenas em seu aspecto negativo. Deixamos de considerar que ela, assim como outras emoções, pode atuar de forma construtiva ou destrutiva nos processos de contato e no desenvolvimento de subjetividades, não em decorrência de sua natureza, mas da sua função no campo.

Com isso, a inveja pode ser criativa ou atender, cronicamente, as nossas defesas; pode ser cooperadora do nosso crescimento ou destrutiva a ele. O que caracteriza essa distinção é o fato de, em determinadas circunstâncias, se tornarem fixas, perderem a capacidade criativa, que é a condição necessária ao crescimento, ao desenvolvimento, à atualização e à integração de potencialidades alienadas do self. De acordo com Byington (2002), desqualificamos a inveja, porque nos assustamos e nos afligimos com sua intensa capacidade transformadora da vida, que é seu potencial criativo. $\mathrm{E}$, quando negamos a inveja, fazemos a mesma coisa com nosso desejo e ficamos paralisados.

Nós, gestalt-terapeutas, ao rompermos com uma visão dualista e dicotomizada que não considera a totalidade, temos todo um aparato conceitual que fundamenta uma visão dialética das emoções e dos aspectos da personalidade, trazendo essa noção, por meio da integração de polaridades, como condição de crescimento. Assim, temos instrumentos para compreender que: a inveja, em seu aspecto funcional, pode aumentar o nosso potencial criativo, ampliando possibilidades de contato e awareness de sentimentos ocultos e capacidades subestimadas que podem mobilizar processos de mudanças, nos impulsionando no caminho da autoatualização.

A ampliação do contato com esse afeto pode, portanto, integrar partes alienadas do self projetadas no outro. Se as ocultamos, disfarçamos ou fugimos de suas mensagens, perdemos grandes oportunidades de conhecer, de forma mais profunda, a nossa própria 
verdade. Em seu aspecto disfuncional, pode nos tornar cegamente orientados por ela, por meio da negação e, em casos extremos, instigar o pior que existe em nós, como o desejo de destruir o outro. Não deve ter sido por outro aspecto, senão esse, o que tornou a inveja tão temida e incluída nos sete pecados capitais.

Segundo Robine (2006), a negação é uma recusa não consciente em lidar com o afeto, e toda forma de projeção é uma negação. Nessas condições, podemos concluir que o fluxo de awareness fica bloqueado, e a inveja se torna patológica; uma gestalt fixa que pode acionar um processo destrutivo ou autodestrutivo, por meio da fixidez, gerando sintoma.

Necessitamos deixar de negar a existência da inveja, pois, desse modo, a reprimimos. Para ajudarmos o cliente a identificar sua inveja, é importante levarmos em conta, como nos alerta De Botton (2014), que não sentimos inveja de todo mundo. Invejamos aquelas pessoas que sentimos que somos a elas semelhantes. $O$ que nos causa inveja, desejo, ressentimento, infelicidade é tomarmos conhecimento de que pessoas que fazem parte de nosso grupo de referência conquistaram coisas que não conquistamos. Mesmo que sejam pequenas vantagens, é o suficiente para sentirmos que poderíamos ser um pouco diferentes e melhores do que aquilo que somos no momento.

Ao ajudarmos o cliente a entrar em contato com a capacidade criativa da sua inveja, precisamos ficar atentos para não atendermos as suas expectativas de querer eliminá-la, tentando mostrar-lhe o quanto ele é bom, revelando-Ihe que tem tanto potencial quanto a pessoa de quem sente inveja ou o quanto pode conseguir realizar o que deseja. Se escolhermos esse caminho, estamos eliminando a sua angústia e, juntamente com ela, a possibilidade de a pessoa aproximar-se do que Ihe falta, o qual, muitas vezes, pode não ser o objeto de desejo explícito que move sua inveja. O melhor a fazer é permitir que ela venha à luz, reconhecê-la, acolhê-la e que, por meio dela, possamos nos dar conta do tamanho que podemos ter, do jeito que podemos ser, sem perseguirmos o modelo a ser alcançado.

Imersos, como estamos no culto à felicidade, precisamos abrir espaço na terapia para que o cliente possa expressar a sua inveja e toda dor, ansiedade e sofrimento que podem vir acompanhados da consciência desse sentimento, de tal forma que ele o ajude a encontrar o caminho do seu coração e não seja instrumento de opressão. Que ele possa ficar em sua companhia sem que precise, para isso, sacrificar ou destruir o que é belo no outro em nome do seu progresso pessoal. 


\section{A Gestalt-terapia e a sociedade do hiperconsumo}

Diante do exposto, está compreensível o nosso desafio como terapeutas, qual seja: ajudar nosso cliente a formar fronteiras de contato menos permeáveis ao que ele experimenta como desprezo do outro, a sustentar o seu senso de valor pessoal, sua honra e dignidade quando o mundo the destitui desse reconhecimento.

$\mathrm{Na}$ terapia de abordagem gestáltica, os nossos clientes podem ter oportunidade de aprender a ver a sua própria imagem no espelho, e não a imagem que os ensinaram a ver. Podem ter oportunidade de ajustar sua sintonia consigo mesmos, encontrando valor e sentido naquilo que podem ser a cada momento. A Gestalt-terapia é uma constante renovação do convite a ampliar os sentidos e intensificar 0 contato, a fim de que o cliente possa discriminar o que é dele e o que é do outro, descolar a percepção do seu próprio valor do julgamento do outro ou do outro introjetado. É uma oportunidade, e por vezes a única condição, de se conseguir discriminar em que se fundamenta a opinião do outro, de tal forma que o indivíduo se dê conta da estreiteza desse arbítrio. O terapeuta é o artesão que ajuda o cliente a talhar, lapidar a pedra bruta, retirar pedaços colados nele que não são dele e auxilia a devolver ao outro o que é dele.

Em terapia gestáltica, a pessoa pode encontrar caminhos para abrir mão de estar sempre superando a si mesma na busca repetitiva e destrutiva daquele amor que nunca teve. Mais ainda, essa abordagem, por estar liberta do ideal de progresso da cultura do consumo, pode ajudar o indivíduo a esculpir sua vida baseado no seu desejo genuíno. O desafio do cliente reside em ampliar o olhar para si mesmo e descobrir nuanças de possibilidades de ser criativo na construção de um projeto que não esteja corrompido por um sistema de valor dominante que condena algumas pessoas ao fracasso.

Vale lembrar, no entanto, que nós terapeutas não estamos imunes aos apelos da sociedade da satisfação total. Sendo assim, para que a terapia reflita os propósitos acima citados, o terapeuta precisa estar em bastante sintonia com seus sentimentos, memórias e feridas narcísicas. Isso decorre do fato de que as necessidades emocionais, quando não conhecidas, têm a possibilidade de se tornarem exigentes, e os clientes podem, então, serem postos a serviço de satisfazer seu desejo de status, o que pode ser um degrau ou um instrumento para o terapeuta obter admiração e respeito. Definitivamente, eles não estão ali para isso, pois tudo que os clientes precisam é experimentar o que Bauman (2009) denomina de o prazer extremamente intenso do EU-TU, o prazer dos prazeres: a ligação. O prazer de fazer uma diferença, de sentir-se necessário.

A Gestalt-terapia trabalha no sentido contrário à ilusão da felicidade sustentada nas conquistas insaciáveis do ter e do saber. Sendo assim, a felicidade em que acreditamos é a que vem por acréscimo às 
emoções verdadeiras, às alegrias e às dores que podem ser sentidas, e não amordaçadas pelo peso do "bem-estar". Afinal, o bem-estar que buscamos é aquele de poder acompanhar a experiência, de estar inteiramente presente, estar disponível ao que é possível de se ter e viver. Não acreditamos em felicidades baseadas em interesses privados, mas naquela que seja fruto, não de relações utilitaristas, mas de relações baseadas no cuidado.

Não acreditamos em felicidade associada à plenitude do bem-estar interior que venha da incessante luta pela completa autorrealização (que é em si mesma inalcançável) e da admiração e respeito que consideramos que só vamos conquistar diante dessa forma de autorrealização. Podemos deduzir que, se a nossa abordagem de psicoterapia pode trabalhar com um sentido de felicidade, este vem do significado de autoatualização e de crescimento, não de autorrealização hedonista fomentado pela cultura do consumo. Visamos ao crescimento como possibilidade de ampliação de contato com nossos sentimentos genuínos e, assim, dispondo deles, podermos olhar para nossa história com outra perspectiva e estarmos inteiramente presentes no agora. Na concepção da Gestalt-terapia, o indivíduo cresce quando está livre para fazer contato com a situação presente e, então, poder realizar escolhas com responsabilidade. Essa abordagem está apoiada em uma teoria que sustenta a responsabilidade e o envolvimento do indivíduo frente ao mundo (Robine, 2006).

O conceito de autoatualização na Gestalt-terapia é ampliado para uma visão cada vez menos centrada no indivíduo, e mais no campo. Entendemos que o indivíduo só existe em contato. Tudo o que ele vive ocorre numa fronteira organismo-ambiente. Ao destacar a mudança de enfoque dualista para uma visão de campo, Perls, Hefferline e Goodman (1997, p. 43), afirmam que ". . . toda função humana é um interagir num campo organismo/ambiente, sociocultural, animal e físico." Portanto, se não existimos isolados do mundo, também não crescemos sozinhos. Consequentemente, não atualizamos nosso potencial, aquilo que temos possibilidade de ser a cada momento, imersos em nossa vida privada, mas em relação com o outro, que também cresce conosco.

Como tão bem esclarecem Hycner e Jacobs (1995 como citado em Wollants, 2018, p. 139): "Gestalt-terapeutas dão menos ênfase ao indivíduo como uma entidade separada do que à relação pessoamundo. O foco é na atualização das interações em oposição à autoatualização da pessoa individualmente. Gestalt-terapeutas estão interessados na atualização relacional".

Ainda temos uma grande responsabilidade como gestalt-terapeutas nesse mundo hiperindividualizado. Apesar de os ideais de amor, de cuidado e solidariedade com o outro sobreviverem em meio ao individualismo desenfreado, somos convocados, se quisermos ter um 
posicionamento político em nossa atuação, a ajudar o outro a vivenciar, no encontro conosco, a experiência da dignidade de ser acolhido com respeito por quem ele pode ser no momento e viver, de fato, a relação terapêutica como um encontro. Mais além, precisamos efetivamente, ampliar em nossos atendimentos a vivência de campo, a noção de fronteiras para além da relação interpessoal que está mais temporariamente ligada ao indivíduo em si, ajudando-o a ampliar sua sensibilidade à natureza estética do mundo, percebendo valor e profundidade em todos os seres animados ou inanimados, descentralizando-se de si mesmo.

Como nos lembra Hilman (1989), todos os seres do mundo, inclusive os objetos, têm pele, cheiro, forma, textura e cor, podendo nos dizer muito com sua linguagem e nos ensinar algo. Eles também se expressam por meio de sua patologia, como por exemplo, na poluição do ar, dos rios e mares, na violência, no abando de crianças e nas sujeiras das ruas. Tudo no mundo é uma apresentação fenomenológica. Possui profundidade, memória, um propósito; é, então, uma subjetividade.

Ao buscar relações entre a Gestalt-terapia, a corporeidade e a estética, Alvim (2007) apoiou-se na concepção de estética fenomenológica desenvolvida por Mikel Dufrenne, filósofo contemporâneo francês que afirma:

A percepção estética é, de fato, a percepção real, aquela que só quer ser percepção, sem se deixar seduzir pela imaginação, que convida a vaguear em torno do objeto presente, ou pelo intelecto que, para dominar o objeto, procura reduzi-lo a determinações conceituais; enquanto a percepção ordinária sempre tentada pela intelecção desde que tem acesso à representação - procura uma verdade sobre 0 objeto. (Dufrenne, 2004, p. 80 como citado em Alvin, 2006, p. 138).

Somos terapeutas do contato. Acreditamos nos sentidos como forma de fazer contato e estar em relação para além do caráter utilitário e de prazer imediato que as pessoas e coisas podem ter para nós e que faz com que tudo, até as pessoas, sejam descartáveis. Com nossa abordagem de campo, temos oportunidade de dar atenção não só ao mundo interior da pessoa, mas também para todas as coisas do mundo, considerando-as como são e o que têm a nos dizer sobre elas, não apenas como uma projeção de nossos conteúdos interiores. Dessa forma, em nosso consultório, teremos uma ação política, uma vez que estaremos ajudando nossos clientes e a nós mesmos a percebermos que também podemos participar da reconstrução de um mundo onde possamos viver uma ecologia profunda, um relacionamento recíproco de respeito, cuidado e afeto entre todos os seres. 
Os valores da sociedade do hiperconsumo nos levam a uma consciência de liberdade individualizada interessada no privado: eu, minhas conquistas, meu sucesso. A Gestalt-terapia, com seus conceitos de campo, self - que se expressa no contato e seu foco no "entre" e não no " intra" -, nos leva à ampliação de uma consciência de liberdade coletiva, pois considera a estética do contato. Não importa apenas como nos sentimos, mas como sentimos o mundo e como ele nos sente. Importa o que há de belo dentro e fora de nós, não no status que conquistamos ou no valor utilitário que o outro e as coisas podem ter para nós, mas no que somos e na substância e profundidade que as coisas têm.

Orientando o fazer da psicoterapia pelo paradigma do Cuidado, da Ecologia Profunda e da Reciprocidade, ela será um lugar em que possamos aprender a reverenciar o outro, ser aceitos com a nossa inveja, nos envergonhar, nos perdoar por aquilo que não pudemos ser e honrar o que, no momento, podemos ser. Concluímos este artigo, fazendo nossas as palavras de Marta Medeiros (2013):

. . que nossos sentimentos não sejam em vão, que percebamos o ridículo das ideias estanques e inflexíveis, que saibamos apreciar o belo, que não tenhamos tanto medo da palavra felicidade, que designa apenas o conforto de estar onde se está e de ser o que se é. (Medeiros, 2013, p. 26).

Que assim seja!

\section{Considerações finais}

A sociedade do hiperconsumo está centrada em um valor de felicidade baseado em conquistas intermináveis de obtenção de melhor qualidade de vida em aspectos ligados ao maior conforto, ao lazer e ao bem-estar psicológico e físico. O valor pessoal do indivíduo passa a se dar por meio dessas conquistas, que dependem de seu esforço e competência pessoal, e que, portanto, se não forem alcançadas, geram sentimentos de humilhação, vergonha e inveja. É importante que na clínica, o terapeuta possa dar atenção a esses sentimentos e, principalmente, saiba acolher a inveja, sentimento tão estigmatizado como destrutivo.

A Gestalt-terapia, por ser a terapia do contato e confiar nos sentidos como forma de se ter uma relação genuína e não utilitária com o outro, possibilita trazer uma contribuição revolucionária, pois, com uma experiência nessa abordagem, 0 indivíduo pode ter a oportunidade de ser acolhido com dignidade e respeitado, sendo aquilo que está podendo ser, ter e saber em cada momento da sua vida. Pode ainda contribuir para relações ecologicamente profundas, 
porque o terapeuta, ao descentralizar o seu foco na vida interior e privada do cliente, o ajudará a descobrir, no encontro sensível com o outro (pessoas e objetos), valor, profundidade e respeito.

\section{Referências}

Alvim, M. B. (2007). Experiência Estética e corporeidade: fragmentos de um diálogo entre Gestalt-Terapia, Arte e Fenomenologia. Estudos e Pesquisas em Psicologia, 7(1), 138-146. Recuperado de http://www.revispsi.uerj.br/v7n1/artigos/pdf/v7n1a12.pdf

Bauman, Z. (2008). Vida para consumo. Rio de Janeiro, RJ: Zahar.

Bauman, Z. (2009). A arte da vida. Rio de Janeiro, RJ: Zahar.

Bauman, Z. (2017). Estranhos à nossa porta. Rio de Janeiro, RJ: Zahar.

Birman, J. (1999). A psicopatologia na pós-modernidade. As alquimias no mal-estar da atualidade. Revista Latinoamericana de Psicopatologia Fundamental, 2(1), 35-49. doi: 10.1590/1415-47141999001003

Byington, C. A. B. (2002). Inveja criativa: o resgate de uma força transformadora. São Paulo, SP: Religare.

De Botton, A. (2014). Desejo de status. Porto Alegre, RS: L\&PM Editores.

Goffman, E. (1963). Estigma: Notas sobre a Manipulação da Identidade Deteriorada. Rio de Janeiro, RJ: LTC.

Guiddens, A. (2002). Modernidade e identidade. Rio de Janeiro, RJ: Zahar.

Hilman, J. (1989). Entre Vistas: conversas com Laura Pozzo sobre psicoterapia, biografia, amor, alma, sonhos, trabalho, imaginação e o estado da cultura. São Paulo, SP: Summus.

Lewis, H. B. (1971). Shame and guilt in neurosis. New York: International Universities Press.

Lipovetsky, G. (2007). A felicidade paradoxal: ensaio sobre a sociedade de hiperconsumo. São Paulo, SP: Companhia das Letras.

Lipovetsky, G. (2015). A sociedade da decepção. Lisboa: Portugal Edições 70.

Medeiros, M. (2013, novembro 3). Uma oração para os novos tempos. Perca tempo - O Blog do Murilo. Recuperado de http://avaranda.blogspot.com/2013/11/uma-oracao-para-osvivos-martha-medeiros.html

Moore, T. (1993). Cuide de sua alma. São Paulo, SP: Siciliano.

Perls, F., Hefferline, R., \& Goodman, P. (1997). Gestalt-terapia. São Paulo, SP: Summus.

Robine, J. (2006). O self desdobrado: perspectiva de campo em Gestalt-terapia. São Paulo, SP: Summus. 
WHO. World Health Organization. (1946). Constitution of the World Health Organization. Basic Documents. Genebra: World Health Organization.

Wollants, G. (2018). Self da situação. In J. Robine (Ed.), Self: uma polifonia de Gestalt-terapeutas contemporâneas (pp. 135-146). São Paulo, SP: Escuta.

\section{Endereço para correspondência \\ Carla Machado Alegria}

Rua Arízio Gomes Batista, 50, casa 18, Jardim Flamboyant, CEP 28905-310, Cabo Frio - RJ, Brasil

Endereço eletrônico: alegriamcarla@gmail.com

Recebido em: 13/10/2019

Reformulado em: 05/01/2020

Aceito em: 08/01/2020

\section{Notas}

* Psicóloga graduada pela FAMATH. Gestalt-terapeuta. Psicóloga concursada em saúde pública desde 1992, atuando há quatro anos no Programa IST/Aids. Especialista em Educação em Saúde Pública pela UFF. Mestre em HIV/Aids pela UNIRIO. Professora do curso de Pós-graduação em Gestalt-terapia da Universidade Veiga de Almeida.

Este artigo de revista Estudos e Pesquisas em Psicologia é licenciado sob uma Licença Creative Commons Atribuição-Não Comercial 3.0 Não Adaptada. 